\title{
New technology for waste fluorescent lamps treatment in Lithuania - characterisation and environmental impact
}

\author{
I. Urniezaite ${ }^{1}$, D. Jankunaite ${ }^{1} \&$ E. Griskonis ${ }^{2}$ \\ ${ }^{1}$ Department of Environmental Engineering, \\ Kaunas University of Technology, Lithuania \\ ${ }^{2}$ Department of General Chemistry, Kaunas University of Technology, \\ Lithuania
}

\begin{abstract}
Treatment of waste fluorescent lamps, which are widely used all over the world, is a very important field of environmental research. Due to the presence of mercury vapour in these lamps, this kind of waste requires special attention to its disposal. This study aims to evaluate the environmental impact of fluorescent lamps and to describe the principal aspects of new technology used for their treatment in Lithuania.

The main parameters in this treatment process are mercury and manganese concentrations in the treatment of residual waste of fluorescent lamps. Mercury concentration in fractionated treatment residuals was determined by complexonometric titration and the manganese concentration was determined by the atomic absorption method. The results, obtained in the study, show manganese and mercury content in fluorescent lamp treatment products and the main physical parameters of these treatment products. This study revealed that concentrations of metallic mercury and water soluble mercury salts in the examined samples are within the permitted limits. Also, this paper presents residuals X-ray analysis results.

Results of this study show that the products of waste fluorescent lamps treatment can be treated as environmentally friendly, according to their solubility in water. It gives an opportunity to look for more possibilities of this product's disposal. As the presented treatment technology is relatively new and used to treat only small amounts of waste fluorescent lamps, this technology could be modified for larger productivity. Studies of this technology should go further in the aspects of different ways of treating the disposal of products, development of technology, etc.
\end{abstract}

Keywords: waste, fluorescent lamps, complexonometric titration, atomic absorption, xrd analysis, hazardous waste, heavy metals, mercury. 


\section{Introduction}

Fluorescent lamps are widely used all over the world because of their long life and efficient energy use. Therefore, waste fluorescent lamps utilization is a very important field of environmental research. Due to the presence of mercury vapour in these lamps, used lamps are recognized as hazardous waste and require special attention to their disposal. There are different possibilities for this kind of waste disposal - from recycling, recovering of some materials or even the simple, safe disposal of rare chemical elements.

There are studies made on the rare earth metals recovered from fluorescent lamps. While mercury and glass cullets can be recovered from the waste lamps, luminescent materials containing rare earth elements are dumped into landfills without recovery. Recycling of the rare earth elements, such as Y, Eu, La, Ce and $\mathrm{Tb}$ is not considered practical due to the lack of an available method [1]. Also, experiments are made with waste phosphors collected during the recycling of end-of-life fluorescent lamps to obtain a highly enriched phosphors product as a starting material for the better extraction of rare earth elements [2]. Fluorescent lamps can be recycled by crushing the tubes and splitting them into component parts, allowing mercury and other components (mainly glass) to be recovered [3].

Lithuania still has a problem with the safe waste fluorescent lamps treatment as the current economical and technological situation in Lithuania means it is not very feasible to apply high-tech management of waste fluorescent lamps, although problem exists and special attention is paid for finding the best treatment opportunities. New waste fluorescent lamps treatment technology presented in this work is not very complex, but is effective for safe waste lamp disposal.

\section{Technology}

Part of the mercury present in fluorescent lamps is in the vapour phase and it is assumed to be emitted to the atmosphere immediately upon the lamp breaking. The components of the lamp (the phosphor powder, end caps, glass) also contain some bound mercury. Hereafter, the presented technology is designed to avoid mercury emissions to the atmosphere and to transfer metallic mercury into inorganic mercury salts.

Technology of waste fluorescent lamps treatment was developed in Kaunas University of Technology, Department of General Chemistry, together with JSC "Multiimpex". It was patented in 2002 as the Lithuanian patent [4]. The principal scheme of this technology is shown in fig. 1. This technology satisfies the requirements of Integrated Pollution Prevention and Control Reference Document on Best Available Techniques for the Waste Treatments Industries in category of Physico-chemical treatment of solid wastes [5].

Waste fluorescent lamps are placed on the loader (3), grabbed and transported to the reactor camera (2) through the barrier of demercurizing liquid. As the loader moves, every lamp goes through a breakage device (5) and is broken. 
Glass breakage drops onto the plate (14) and is transported through the glass crusher (15) to the discharge loader (16), which transfers waste glass to the container (17).

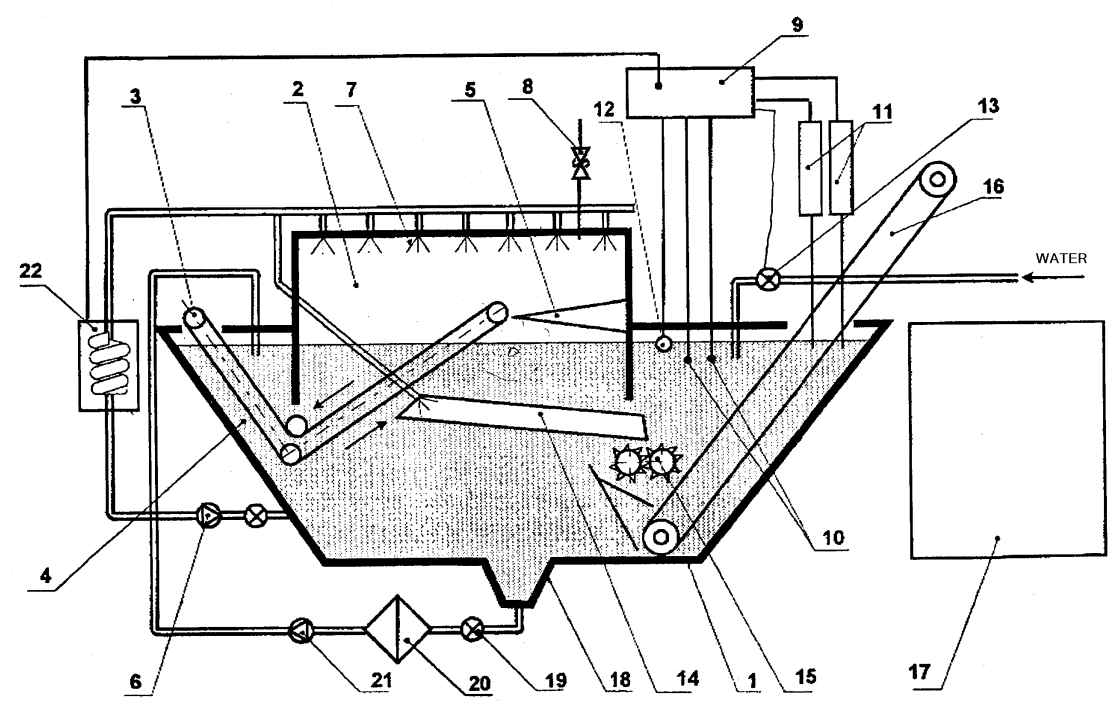

Figure 1: $\quad$ Scheme of industrial device for waste fluorescent lamps disposal.

Demercurizing liquid, used for mercury fixation, consists of water soluble manganese and chlorine compounds. The reactor is filled with $1 \mathrm{~m}^{3}$ of reacting mixture (4). The top level of demercurizing liquid is higher than the directive plate (14). Metallic mercury vapour reacts with demercurizing mixture and forms non-soluble compounds. Demercurizing liquid goes trough the recycling pump (6) and is constantly sprayed trough the sprayers (7) into the reactor. Metallic mercury vapour from the broken lamps is present in the reactor and demercurizing liquid is sprayed until concentration of mercury vapour attenuates to the permissible limit. The big surface area of liquid drops ensures high effectiveness of mercury vapour fixation. Part of the used liquid is directed to the glass breaking device to ensure a reaction of mercury drops with the demercurization liquid and good liquid mixing.

Insoluble mercury and manganese compounds, formed during this process, are collected in the hollow at the bottom of the reactor (18). Then reacting liquid is pumped back to the reservoir through the valve (19); insoluble sediments are suspended in the filter (20). Soluble mercury and manganese compounds are accumulating in the demercurizing liquid and are isolated from the liquid during its processing.

This kind of industrial device can be used as a stationery treatment system or be installed in a vehicle and used as mobile treatment equipment. 


\section{Materials and methods}

Solid residuals from waste fluorescent lamps treatment are the target of this study. These insoluble sediments, shown in the fig. 2, contain glass breakage and a mixture of different small particles. Experimental samples were taken from the collecting filter (20) of the presented treatment device.

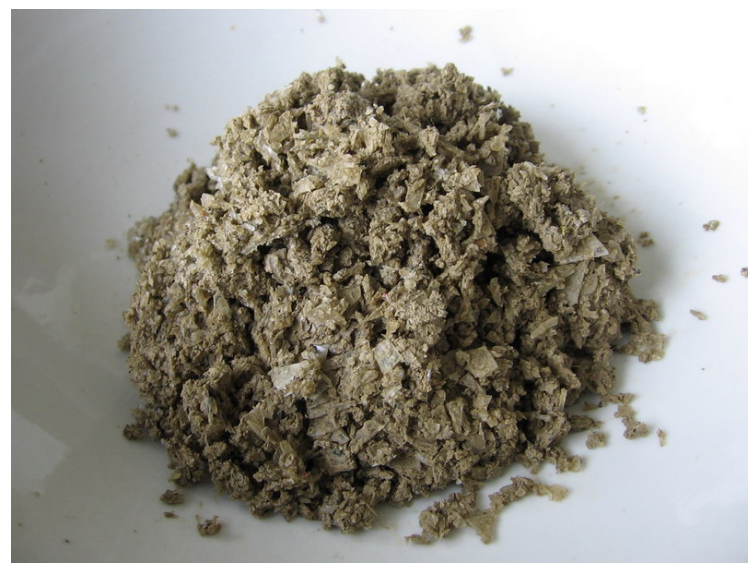

Figure 2: Waste fluorescent lamps treatment residuals.

Mercury and manganese concentrations in waste fluorescent lamps treatment residuals are the most important parameters of this treatment process and the object of this study. Samples were separated to glass and remaining solid fraction by rinsing out and then drying at room temperature. Separated solid residuals were analysed on purpose to identify how mercury and manganese are distributed between glass and the remaining residuals fraction. Dry solid fractions were dissolved in a mixture of hydrochloric and nitric acids. Mercury and manganese concentrations were determined in both solid fractions solutes and swilling water. Mercury concentration was determined by complexonometric titration method [6] and manganese concentration was determined by the atomic absorption method [7] using a Perkin Elmer 403 AA spectrophotometer.

Waste fluorescent lamps can contain synthetic minerals, mainly apatites [3], therefore X-Ray diffractometry (XRD) was used to identify the minerals present in residuals. The XRD data were collected with a DRON-6 X-ray diffractometer with Bragg-Brentano geometry using Ni-filtered $\mathrm{CuK}$ radiation and graphite monochromator, operating with the voltage of $30 \mathrm{kV}$ and emission current of 20 $\mathrm{mA}$.

\section{Results and discussion}

The results obtained in the study and presented in Table 1 show manganese and mercury content in waste fluorescent lamps treatment residuals and the main physical parameters of the analysed samples. Manganese is present in the 
residuals mainly as a constituent of insoluble manganese dioxide $\mathrm{MnO}_{2}$ and soluble manganese chloride $\mathrm{MnCl}_{2}$. Insoluble mercury sulfide $\mathrm{HgS}$ and mercury chloride $\mathrm{HgCl}$ are presumed as the main mercury containing compounds in the residuals [4].

Table 1: $\quad$ Results of the experiment.

\begin{tabular}{|l|c|c|}
\hline Residuals components & In wet mass & In dry mass \\
\hline Moisture content, $\%$ & 14,69 & - \\
\hline Glass fraction, $\%$ & 57,73 & 67,66 \\
\hline Remaining fraction, \% & 27,59 & 32,34 \\
\hline Manganese content, $m g / k g:$ & 10408 \\
\hline Total quantity in waste lamps & 8881 & - \\
\hline Quantity in rinsing water & 1,63 & 189 \\
\hline In glass fraction & - & 10219 \\
\hline In remaining solid fraction & - & 300 \\
\hline Mercury content, $m g / k g:$ & 255,75 & - \\
\hline Total quantity in waste lamps & 0,00 & 283 \\
\hline Quantity in rinsing water & - & 17 \\
\hline In glass fraction & - & \\
\hline In remaining solid fraction & \multicolumn{2}{|l|}{} \\
\hline
\end{tabular}

Results of this experiment revealed that metallic mercury and water soluble mercury compounds were not found in waste fluorescent lamps treatment residuals. A major part of the mercury compounds remain on the glass fraction, but it is immobilized and cannot be spread into the atmosphere. Manganese amount in residuals is $10408 \mathrm{mg} / \mathrm{kg}$ and $98 \%$ of it is concentrated in the remaining fraction of residuals. The amount of manganese in glass fraction reaches only $189 \mathrm{mg} / \mathrm{kg}$ and in the remaining fraction is $10219 \mathrm{mg} / \mathrm{kg}$. Mercury distribution is reverse: $94 \%$ of mercury stays in the glass fraction. It can be explained by possible mercury binding to the glass luminophor coating.

The manganese and mercury amount in the water soluble part of the waste fluorescent lamps treatment residuals does not exceed limits set in the soil quality standard of Lithuania HN 60:2004 [8]. Normative for manganese quantity in soil is $1500 \mathrm{mg} / \mathrm{kg}$ and measured water soluble concentration is 1,63 $\mathrm{mg} / \mathrm{kg}$. Allowable mercury amount in soil is $1,5 \mathrm{mg} / \mathrm{kg}$, but no water soluble mercury was detected in the analysed samples.

XRD analysis confirmed that minerals fluorapatite and hydroxylapatite dominate in the samples of waste fluorescent lamps treatment residuals. Basic fluorapatite and hydroxylapatite diffraction reflections were identified in the diffractogram with D-spacings $0.281 ; 0.277 ; 0.271$ (fig. 3). Apatites are calcium phosphate minerals that may also contain fluoride, chloride, hydroxyl or carbonate, depending upon variety. It is assumed that these minerals form from the phosphor coating that is applied to the fluorescent lamps before use [3]. It 
can be suggested that as heavy metals can be substituted into the mineral structure of apatites, it is possible that mercury can bind to these minerals. This would explain high mercury concentration on glass fraction of the analysed residuals.

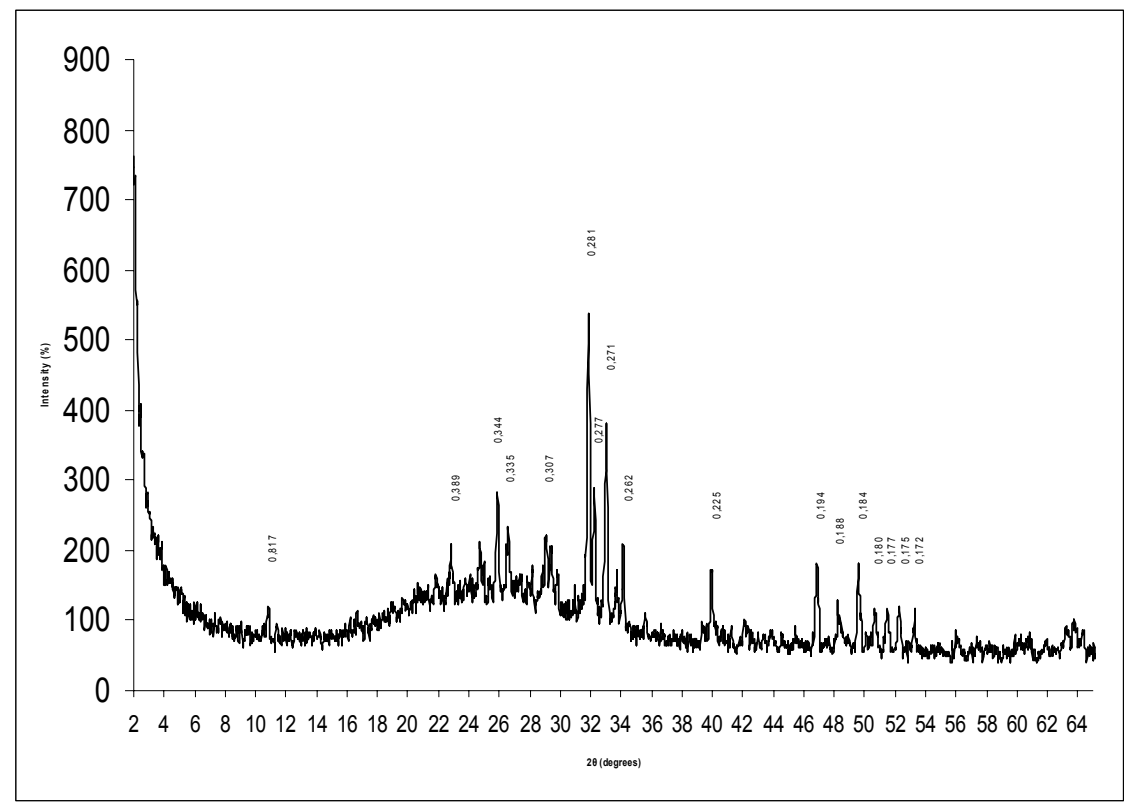

Figure 3: $\quad$ XRD spectrum of waste fluorescent lamps treatment residuals.

\section{Conclusions and recommendations}

Herein, presented waste fluorescent lamps treatment technology is classified as physico-chemical treatment of solid wastes by IPPC BAT for Waste Treatments Industries [5] and is designed to avoid mercury emissions to the atmosphere and to transfer metallic mercury into inorganic mercury salts.

Analysis of waste luminescent lamps treatment residuals showed different manganese and mercury distribution between glass and the remaining fraction of the residuals. Mercury is concentrated on the glass fraction while a major part of the manganese is in the remaining residuals fraction. XRD analysis showed minerals fluorapatite and hydroxylapatite present in waste fluorescent lamps treatment residuals. These minerals, formed on the glass, from the phosphor coating, can be the main mercury binding materials in the glass fraction.

According to analysis of residuals solubility in the water, immobilization of mercury during the treatment process is successful and the presented waste fluorescent lamps treatment technology can be called environmentally friendly and gives an opportunity to look for more possibilities of residuals disposal. 
As the treatment technology studied is relatively new and used to treat only small amounts of waste fluorescent lamps, this technology could be modified for higher productivity. Studies of this technology should go further in respect of the possibilities of different ways of treatment for the products' disposal, technology development, etc.

\section{Acknowledgement}

This research work was done with the support of JSC "Multiimpex".

\section{References}

[1] Shimizu, R., Sawada, K., Enokida, Y. \& Yamamoto, I., Supercritical fluid extraction of rare earth elements from luminescent material in waste fluorescent lamps. The Journal of Supercritical Fluids, (33), pp. 235-241, 2005.

[2] Hirajima, T., Sasaki, K., Bissombolo, A., Hirai, H., Hamada, M., \& Tsunekawa, M., Feasibility of an efficient recovery of rare earth-activated phosphors from waste fluorescent lamps through dense-medium centrifugation. Separation and Purification Technology (44), pp. 197204, 2005.

[3] The NCBS/ Nov 01/2132/ Sustainable markets for waste glass from fluorescent tubes and lamps. Final report, January 2002.

[4] Lithuanian patent Nr. 4954, H01J 9/39. Method for processing mercury lamps and device for implementation of it / R.A. Plungè, A. Plungè, E. Griškonis. - 20020925.

[5] European Commission - European IPPC Bureau, "Reference Document on Best Available Techniques for the Waste Treatments Industries" (BRef on Waste Treatments). Adopted August 2006.

[6] Lurje J.J., Chimicheskij analiz proizvodstvennych stochnych vod, pp. 160166, 1974 (in Russian).

[7] Sbornik metodik po opredeleniju koncentracij zagriazniajushchich veshchestv v promyshlennych vybrosach. - L. „Gidrometeoizdat“, 1987, p. 161-164 (in Russian).

[8] Lietuvos higienos norma HN 60:2004. Pavojingu cheminiu medziagu didziausios leidziamos koncentracijos dirvožemyje / Maximum Permissible Concentrations of Hazardous Chemical Materials in Soil. Oficialusis leidinys. Lietuvos Respublikos sveikatos apsaugos ministerija. - Vilnius, 2004. 